\title{
Effect of functional electrical stimulation on postural control in children with hemiplegic cerebral palsy: a randomized controlled trial
}

\author{
Shamekh Mohamed El-Shamy* (D) and Ehab Mohamed Abd El Kafy
}

\begin{abstract}
Background: Children with cerebral palsy have impairments of postural control during static and dynamic activities. Improving postural control is one of the primary objectives of rehabilitation for children with cerebral palsy. Therefore, the objective of this study was to study the effect of functional electric stimulation on postural control in children with hemiplegic cerebral palsy. A randomized controlled study was conducted on 30 children with hemiplegic cerebral palsy ( 18 boys and 12 girls) between the ages of 8 and 12 years. The children were distributed in two equal groups. The experimental group received functional electrical stimulation (pulse width $300 \mu$ s, frequency $33 \mathrm{~Hz}, 2 \mathrm{~h} /$ day, 3 days/week, / 3 consecutive months) in addition to the traditional physical therapy program. While the control group received the traditional physiotherapy program only for the same duration. The outcomes included postural stability indices that were measured at baseline and following 3 months of intervention using the Biodex balance system.
\end{abstract}

Results: A significant improvement was found in the postural stability indices of children in both groups, comparing their mean values before and after treatment. Furthermore, the results revealed a greater improvement in the postural stability of the experimental group $(P<0.001)$.

Conclusion: Functional electrical stimulation may be a useful tool to enhance the postural stability of children with hemiplegic cerebral palsy.

Clinical trial registration: This study was registered in the ClinicalTrial.gov PRS (NCT04269798). https://register. clinicaltrials.gov/prs/app/action/SelectProtocol?sid=S0009LHP\&selectaction=Edit\&uid=U0003GAl\&ts=4\&cx=74k74l

Keywords: Balance, Biodex, Cerebral palsy, Functional electrical Stimulation, Hemiplegia

\section{Background}

Cerebral palsy (CP) describes a group of movement and posture disorders that cause activity limitations attributed to non-progressive damage to the immature brain [1]. Disabilities are caused by damage to an immature brain or indirectly by compensatory movements during development. Thus, children with $\mathrm{CP}$ generally have various motor impairments, such as muscular weakness, spasticity and incoordination,

\footnotetext{
* Correspondence: smshamy@uqu.edu.sa

Department of Physical Therapy, Faculty of Applied Medical Sciences, Umm Al-Qura University, Makkah, Saudi Arabia
}

(C) The Author(s). 2021 Open Access This article is licensed under a Creative Commons Attribution 4.0 International License, which permits use, sharing, adaptation, distribution and reproduction in any medium or format, as long as you give appropriate credit to the original author(s) and the source, provide a link to the Creative Commons licence, and indicate if changes were made. The images or other third party material in this article are included in the article's Creative Commons licence, unless indicated otherwise in a credit line to the material. If material is not included in the article's Creative Commons licence and your intended use is not permitted by statutory regulation or exceeds the permitted use, you will need to obtain permission directly from the copyright holder. To view a copy of this licence, visit http://creativecommons.org/licenses/by/4.0/.

resulting in balance and walking problems and may limit their participation $[2,3]$.

Hemiplegia is defined as the damage to the ipsilateral upper and lower limbs, the upper limb of which is more seriously affected than the lower limb. Hemiplegia accounts for more than one-third of all types of $\mathrm{CP}$, resulting in impaired functional independence and quality of life [4]. Equinovarus deformity is the most common deformity of the ankle and foot complex in spastic hemiplegia. This deformity is marked by plantar flexion and inversion of the ankle [5]. 
Falling of the foot is an abnormal activation of the muscles of the lower limbs, leading to ineffective foot clearance during the swing phase and reduced stability in the stance phase [6]. These disturbances adversely affect the functioning of balance and walking, which can limit participation in various activities [7].

Children with CP often have problems with their balance and postural responses. These impairments include the normal atypical posture of the body [5], caused by the asymmetric alignment of the posture. This poor posture is one of the major problems for children with hemiplegic CP [8].

Postural control is an essential objective in treating children with CP. Balance and gait training is important in most everyday activities and helps children recover from balance, fall and injury problems [9]. Traditional rehabilitation programs involving stretching, strengthening, positioning, casting, and facilitation of correct movements and postures play a central role in the management of children with CP [10].

Physiotherapy and orthotic interventions are considered central components of $\mathrm{CP}$ multimodal management [11]. In this context, botulinum toxin type A (BoNT-A) is also an important treatment for enhancing function and supporting motor development [12]. Ankle foot orthosis (AFO) may further develop safety and stability in the children's gait; however, AFOs have been criticized for their inconvenient effects on the adaptability of walking, propulsion, esthetics, and comfort [13], which can decrease compliance and satisfaction. In children with hemiplegic $\mathrm{CP}$, the peripheral nerves remain intact. Functional electrical stimulation (FES) is thus an alternative intervention in the management of the CP. FES is the electrical stimulation of the common peroneal nerve, activating the dorsiflexor and evertor muscles of the foot during the swing phase of the gait. Hence, FES works as a dynamic orthosis in rehabilitating children with CP [14-16].

A previous clinical trial has shown that the use of FES in combination with a traditional treatment program may increase improvements in gait pattern and energy expenditure in children with hemiplegic CP [17]. Despite the benefits and advantages of FES, clinical use of FES for improving balance and walking is not yet as common as the other traditional interventions in the management of children with CP. Therefore, this study aimed to assess the effect of FES on postural control in children with hemiplegic $\mathrm{CP}$.

\section{Methods}

This randomized controlled study was approved by the Ethics Committee of the (19-MED-1-01-0003). Parents have signed a consent form approving children to participate in this study. The participating children were selected from the physical therapy department, Maternity and Children Hospital, Makkah, Saudi Arabia. This study was registered in the ClinicalTrial.gov PRS No NCT04269798.

\section{Inclusion and exclusion criteria}

Forty-two children with hemiplegic $\mathrm{CP}$ were initially examined and assessed to determine age, diagnosis, and inclusion and exclusion criteria. A preliminary power analysis (power $=0.95, \alpha=0.05$, effect size $=0.8$ ) resulted in a sample size of 30 children for this trial. The inclusion criteria were as follows: The participating children had a diagnosis of hemiplegic CP confirmed by magnetic resonance imaging (MRI) obtained from their medical records. They are 8 to 12 years old from both sexes. According to the Modified Ashworth Scale, the level of spasticity of the lower limbs varied from grade 1 to grade 2 [18]. According to the Gross Motor Function Classification System (GMFCS), the levels of gross motor function were between levels I and II [19]. The children involved were cognitively competent and capable of understanding and following instructions. According to their medical report, they did not have any serious medical problems. In this study, children were not receiving additional treatment programs to enhance postural control.

The exclusion criteria were as follows: skin diseases and allergic responses to adhesive tape used in this study; any deformities that interfere with lower limb functions; children with pacemakers that are contraindicated by electrical stimulation; children with visual, auditory, or perceptual deficits; children with seizures; and children who received botulinum toxin or other spasticity medications during the past 6 months pre-treatment testing that might affect the results.

Following the screening process, only 30 children met the abovementioned criteria. They were randomly distributed in two equal groups, fifteen children each. The randomization was carried out utilizing the SPSS computer program (version 20; SPSS Inc., Chicago, IL). The control group received the traditional physical therapy program. While the experimental group was given WalkAide FES plus the same traditional program given to the control group. Allocation occurred before the initial assessment. The study plan is shown as a flowchart in Fig. 1.

\section{Postural stability evaluation}

All children were assessed for postural stability before the treatment (pre-treatment) and at the end of 3 months of treatment (post-treatment) by the same examiner who was blinded regarding the children assignment. Postural stability was measured using the Biodex balance system (Balance System SD, Shirely, NY). It is used to assess neuromuscular control by measuring the ability to maintain postural stability over an unstable surface. The Biodex system was used as a valid and 




reliable system to measure dynamic stability limits and fall risk testing. The intraclass correlation coefficients (ICCs) between testers were 0.70 and the intra-tester ICCs were 0.82 [20]. The Biodex is equipped with a high-resolution color touch screen, support rails, and 12 platform control levels. It allows 12 levels of stability (12 is more stable and 1 is less stable).

During the evaluation, children were asked to maintain a centered position on a slightly unstable surface by moving the foot position until it was easy to keep a cursor centered on a screen while remaining in standing position. The child was then asked to hold the foot position until the platform was stable. The test started after the foot angles and heel coordinates were inserted into the system. The child was told to focus on the visual feedback screen directly in front of them, to hold both arms at the side of their body without grasping the handrails, and attempt to keep the cursor in the middle of the bull's eye on the screen. The length of the test was $30 \mathrm{~s}$, and the average of three tests was calculated. When the test was finished, the results were printed.
These results included the overall stability index, the anterior-posterior stability index, and the medio-lateral stability index. Higher values of these results point to problems of balance [21].

\section{Interventions}

\section{Traditional physical therapy program}

Children in both groups received the traditional physical therapy program, which included neuro-developmental treatment for both lower limbs; stretching exercises for tight hip flexors and adductors, knee flexors, and ankle plantar flexors; strengthening exercises for muscles of the trunk and both lower limbs; proprioceptive training; balance exercises in all directions from a standing position; and gait training in a closed and open environment, for three consecutive months $(1 \mathrm{~h} /$ day, 3 days/ week).

\section{Functional electrical stimulation application}

Children in the experimental group were treated with FES using the WalkAide stimulator. The WalkAide FES 
(Innovative Neurotronics, Austin, Texas, USA) (Fig. 2) is a small $(8.2 \times 6.1 \times 2.1 \mathrm{~cm}, 87.9 \mathrm{~g})$ device that conveys electrical stimulation in a synchronized way to stimulate active ankle dorsiflexion during the swing phase of gait. WalkAide FES stimulates the common fibular/peroneal nerve, which innervates tibialis anterior and other dorsiflexors during the swing phase [22].

The WalkAide system was connected directly under the knee with a cuff. The sensors on the device identified changes in the position of the shank and triggered electrical stimulation to activate the dorsiflexion of the ankle during the swing phase of the gait. This equipment was manually synchronized at the beginning with each child's pattern. When the right timing was determined, the program was saved on the device so that the stimulation was constantly transmitted and ended at a particular shank angle. Pulse width has been adjusted to a maximum of $300 \mu$ s and frequency to a maximum of $33 \mathrm{~Hz}$. A therapist can change the intensity $(\mathrm{mA})$ with a dial on the WalkAide system. This equipment recorded operating times and the total number of stimulations. Dorsiflexion was accomplished by common fibular/peroneal nerve stimulation with one electrode placed at the head of the fibula and the other placed on the belly of the tibialis anterior muscle (Fig. 3). For proper care and maximum efficiency, electrodes must be changed every 2-3 weeks of application. The position of the cuff and electrodes on the leg was indicated on the skin using a permanent marker. During EES therapy, children were asked to use WalkAide for at least $2 \mathrm{~h}$ a day, 3 days a week for 12 consecutive weeks [17, $22,23]$.

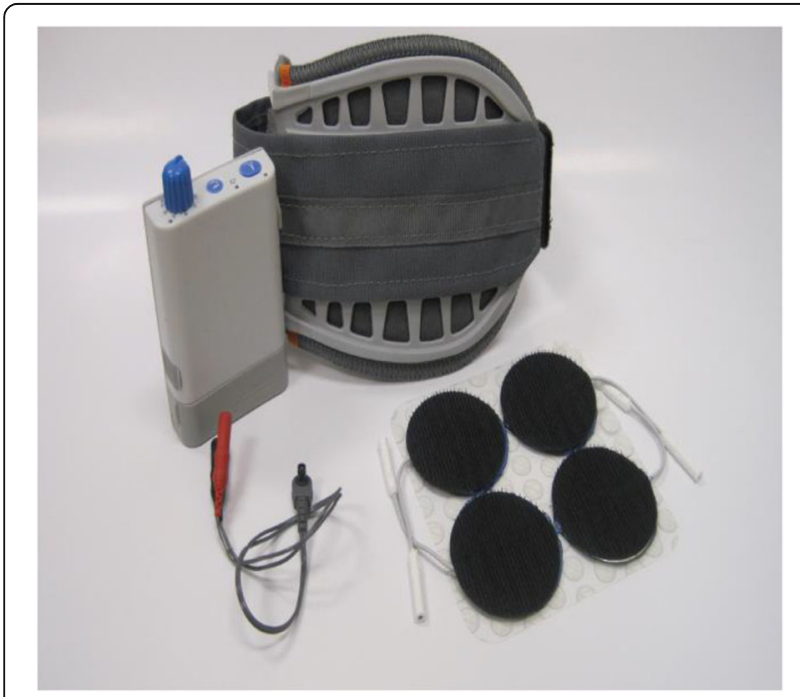

Fig. 2 The functional electrical stimulation system

\section{Statistical analysis}

The data were analyzed using SPSS version 20 (SPSS, Chicago, IL). The descriptive statistics for the mean and standard deviation included the age, weight, height, and GMFCS of the children. Differences between and within the pre- and post-treatment groups were assessed using the student $t$ test. A $P$ value below 0.05 was assumed to be significant.

\section{Results}

Thirty children (18 boys and 12 girls) with hemiplegic $\mathrm{CP}$ have participated in this trial. Children were randomly assigned to experimental and control groups. The demographic and clinical characteristics of the children in both groups are provided in Table 1 . These findings revealed that children in both groups exhibited similar demographic characteristics.

Prior to treatment, there were no statistically significant differences in the mean values of postural stability indices between the experimental and control groups $(P$ $>0.05$ ), as introduced in Table 2. However, there was a statistically significant difference between the mean values of the postural stability indices obtained from the baseline and post-treatment assessments $(P<0.05)$ in both groups. Children in the experimental group demonstrated significant improvement in postural stability compared to children in the control group, as shown in Table 2.

\section{Discussion}

The purpose of this study was to evaluate the effect of FES on postural control in children with hemiplegic CP. The findings of this study demonstrate that a program of combined FES and traditional treatment produced a significant improvement in postural stability compared with a program of traditional treatment alone (Table 2). A significant improvement in postural stability was observed in the two groups after 3 months of treatment. However, greater improvement was achieved in the experimental group.

The fall of the foot results from a lack of dorsiflexion of the ankle during the swing phase of the gait. This lack of ankle dorsiflexion is typically caused by weakness of tibialis anterior muscles, lack of selective voluntary motor control, increased spasticity of the plantar flexor muscles, or a combination of these impairments. Falling feet may cause the feet to slip, scrape the toes, trip, and fall. Therefore, children encountering foot drop may have increased risk of falling [24], which can reduce their routine physical activity and increase the time spent inactive, both of which have negative implications for health [25].

Improved postural stability following FES treatment improves walking speed for children with hemiplegic 


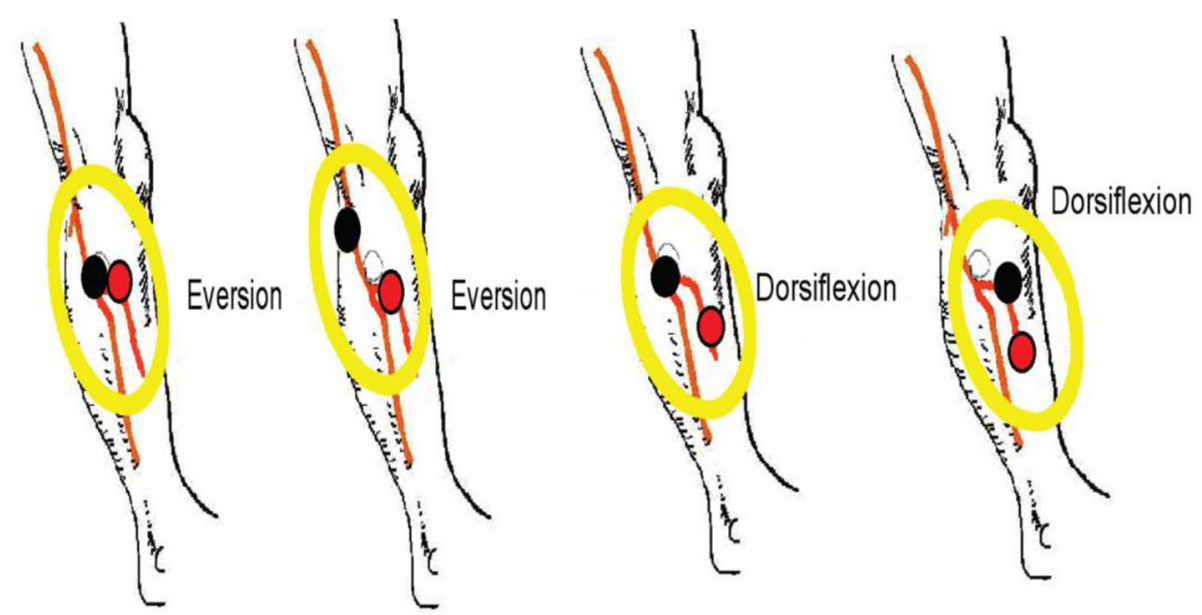

Fig. 3 Placement of electrodes relates to individual anatomical requirements

CP. These improvements are important because the gait patterns of children with $\mathrm{CP}$ are characterized as being slower than their peers, which may restrict their participation in peer equivalent activities required in the school environment [26]. Children with hemiplegic CP have disturbances of balance during walking which limit their participation in equivalent activities. These impairments result in a child's preference for electrical mobility equipment over walking [27]. The treatment using FES in this study is competent to overcome such balance issues.
The improvement in balance after FES treatment is due to improved range of movement (ROM) and reduced spasticity [28]. The mechanism for spasticity reduction and ROM improvements following FES is not surely known, yet a potential hypothesis includes reciprocal inhibition, proposing FES diminishes muscle contraction at the ankle joint by addressing impaired reciprocal inhibition [29-31]. The stimulation of the anterior tibialis muscle would lead to retention of the gastrocnemius muscle, which would make it possible to better reposition the foot for the stance phase of the gait.

Table 1 Demographical and clinical characteristics of the children at baseline

\begin{tabular}{|c|c|c|c|}
\hline \multirow[t]{2}{*}{ Character } & \multirow{2}{*}{$\begin{array}{l}\text { Experimental group }(n=15) \\
\text { Mean } \pm \text { SD }\end{array}$} & \multirow{2}{*}{$\begin{array}{l}\text { Control group }(n=15) \\
\text { Mean } \pm \text { SD }\end{array}$} & \multirow[t]{2}{*}{$P$ value } \\
\hline & & & \\
\hline Age (years) & $10.53 \pm 1.24$ & $10.13 \pm 1.25$ & 0.39 \\
\hline Height (meter) & $1.35 \pm 1.34$ & $1.34 \pm 1.24$ & 0.33 \\
\hline Weight (kg) & $33.13 \pm 1.73$ & $32.4 \pm 1.92$ & 0.28 \\
\hline \multicolumn{4}{|l|}{ GMFCS Level } \\
\hline I & 7 & 6 & 0.72 \\
\hline$\|$ & 8 & 9 & \\
\hline \multicolumn{4}{|c|}{ Spasticity grades } \\
\hline 1 & 3 & 4 & 0.46 \\
\hline $1+$ & 6 & 6 & \\
\hline 2 & 6 & 5 & \\
\hline \multicolumn{4}{|l|}{ Sex } \\
\hline Male & 10 & 8 & 0.47 \\
\hline Female & 5 & 7 & \\
\hline \multicolumn{4}{|l|}{ Affected side } \\
\hline Right & 9 & 11 & 0.45 \\
\hline Left & 6 & 4 & \\
\hline
\end{tabular}

GMFCS gross motor function classification system

* Significant, ${ }^{* *}$ non-significant

Level of significance at $P<0.05$ 
Table 2 Pre- and post-treatment mean values of stability index within each group and between groups

\begin{tabular}{|c|c|c|c|c|c|c|}
\hline \multirow[t]{2}{*}{ Parameters } & & \multirow{2}{*}{$\begin{array}{l}\text { Experimental group } \\
\text { Mean } \pm \text { SD }\end{array}$} & \multirow{2}{*}{$\begin{array}{l}\text { Control group } \\
\text { Mean } \pm \text { SD }\end{array}$} & \multicolumn{2}{|c|}{ 95\% Confidence interval of the difference } & \multirow[t]{2}{*}{$P$ value } \\
\hline & & & & Lower & Upper & \\
\hline \multirow[t]{3}{*}{ Overall stability index } & Pre & $3.37 \pm 0.21$ & $3.28 \pm 0.16$ & -0.05 & 0.24 & $0.21^{* *}$ \\
\hline & Post & $2.25 \pm 0.16$ & $2.75 \pm 0.15$ & -0.62 & -0.38 & $<0.001^{*}$ \\
\hline & $P$ value & $<0.001^{*}$ & $<0.001^{*}$ & & & \\
\hline \multirow[t]{3}{*}{ Antero-posterior stability index } & Pre & $2.85 \pm 0.16$ & $2.78 \pm 0.14$ & -0.04 & 0.18 & $0.29^{* *}$ \\
\hline & Post & $1.8 \pm 0.15$ & $2.26 \pm 0.19$ & -0.59 & -0.33 & $<v 0.001^{*}$ \\
\hline & $P$ value & $<0.001^{*}$ & $<0.001^{*}$ & & & \\
\hline \multirow[t]{3}{*}{ Medio-lateral stability index } & Pre & $2.32 \pm 0.29$ & $2.24 \pm 0.28$ & -0.13 & 0.30 & $0.42^{* *}$ \\
\hline & Post & $1.65 \pm 0.16$ & $2.01 \pm 0.18$ & -0.49 & -0.23 & $<0.001^{*}$ \\
\hline & $P$ value & $<0.001^{*}$ & $<0.001^{*}$ & & & \\
\hline
\end{tabular}

* Significant, ${ }^{* *}$ non-significant

Level of significance at $P<0.05$

This reciprocal inhibition combined with increased awareness due to electrical stimulation [29] may also explain the improvements observed in selective motor control of ankle joint movement [32].

The FES applied while walking has the potential to meet the requirements of motor learning. The best practice guidelines indicate that treatment should be applied frequently with appropriate doses of potential practice in environmentally relevant settings, at the limit of performance [33]. The continued reduction in toe slippage and fall and improved leg balance after FES treatment support this recommendation [34].

Electrical stimulation is a useful tool in combination with work-related functions; it stimulates muscle contractions, is well-tolerated by children, and facilitates motor control [35]. In previous trial, application of FES on various muscle groups of the upper and lower extremities in children with $\mathrm{CP}$ and its impacts on walking speed, spasticity, muscle strength, joint motion interval, and functions were assessed [36]. Combined with a traditional treatment program, FES improves the efficacy of treatment and facilitates functions [28].

Mäenpää and colleagues [32] described that the use of electrical stimulation of the tibialis anterior muscle during ordinary scheduled physical therapy sessions for 1 month in children with spastic hemiplegia or diplegia and weak or absent active ankle dorsiflexion, produced improvement in active and passive motions of the ankle and foot, and the improvement persisted for months after the termination of electrical stimulation treatment.

FES aims to improve dorsiflexion in the swing phase of gait and increases hindfoot eversion and forefoot abduction that converts into initial contact and persists, in spite of the fact that less significantly, during the stance phase of walking. Hence, FES has great potential for improving foot posture in a flexible clubfoot deformation. The indication of FES use can even be extended to patients with dynamic clubfoot deformities in order to improve the repositioning of the clubfoot at initial contact [37].

The results of this study are consistent with that of ElShamy and Abdelaal [17]; they concluded that WalkAide FES might be a useful device for improving gait pattern and energy expenditure in children with hemiplegic CP. Results from this study are also consistent with Pool et al. [23] which demonstrated that short-term community day-to-day FES is an effective activity-based treatment with both orthotic and therapeutic effects. Improvements in community mobility, balance, and spasticity were evident up to 6 weeks post-treatment. This suggests that FES applied during daily walking activities is a feasible treatment option for children with hemiplegic $\mathrm{CP}$.

The limitations of this study include the lack of follow-up data, which reduces the clinical application of our results to the short-term effects of FES. Furthermore, the impact of the physiotherapy program in both groups limits the ability to isolate the FES contribution alone. The results of the present study are encouraging, but further studies with larger samples, long-term results, and possible comparisons with other conservative interventions are necessary. Future studies examining the effect of FES and its role in improving muscle strength and bone mineral density in children with $\mathrm{CP}$ could be useful in guiding clinical practice.

\section{Conclusions}

FES in combination with a traditional physiotherapy program can enhance postural stability improvements in children with hemiplegic CP.

\section{Abbreviations}

CP: Cerebral palsy; BoNT-A: Botulinum toxin type-A; AFO: Ankle-foot orthosis; FES: Functional electrical stimulation; NMES: Neuromuscular electrical stimulation; MRI: Magnetic resonance imaging; MAS: Modified Ashworth scale; GMFCS: Gross Motor Function Classification System; BBS: Biodex balance system; ROM: Range of motion 


\section{Acknowledgements}

The authors would like to thank the Deanship of Scientific Research at Umm Al-Qura University for supporting this work by Grant Code: 19-MED-1-010003.

\section{Authors' contributions}

SME and EMA conceived and designed the study and conducted the data collection. SME and EMA analyzed and interpreted the data in addition to reviewing the final results. SME and EMA provided logistical support and wrote the initial and final drafts of the article. SME and EMA are responsible for the findings and have critically reviewed and approved the final draft of the article. All authors have read and approved the manuscript.

\section{Funding}

The authors confirm that there is no financial support.

\section{Availability of data and materials}

The datasets generated during and/or analyzed during the current study are available from the corresponding author on reasonable request.

\section{Declarations}

\section{Ethics approval and consent to participate}

The study was approved by the Ethical Committee of the Faculty of Applied Medical Sciences, Umm Al Qura University (19-MED-1-01-0003). Parents of all participants signed a written informed consent before starting the study.

\section{Consent for publication}

N/A.

\section{Competing interests}

The authors declare that they have no competing interests.

Received: 15 March 2021 Accepted: 18 July 2021

Published online: 22 December 2021

\section{References}

1. Christensen D, Van Naarden BK, Doernberg NS, Maenner MJ, Arneson CL, Durkin MS, et al. Prevalence of cerebral palsy, cooccurring autism spectrum disorders, and motor functioning-autism and developmental disabilities monitoring network USA 2008. Dev Med Child Neurol. 2014;56(1):59-65. https://doi.org/10.1111/dmen.12268

2. Stavsky M, Mor O, Mastrolia SA, Greenbaum S, Than NG, Erez O. Cerebral palsy-trends in epidemiology and recent development in prenatal mechanisms of disease, treatment, and prevention. Front Pediatr. 2017;5:21.

3. Maenner MJ, Blumberg SJ, Kogan MD, Christensen D, Yeargin-Allsopp M, Schieve LA. Prevalence of cerebral palsy and intellectual disability among children identified in two U.S. National Surveys, 2011-2013. Ann Epidemiol. 2016; 26: 222-226.

4. Rosenbaum P, Rosenbloom L. Cerebral palsy: from diagnosis to adult life. London: Mac Keith Press; 2012

5. Li S. Ankle and foot spasticity patterns in chronic stroke survivors with abnormal gait. Toxins (Basel). 2020;12(10):646. https://doi.org/10.3390/ toxins12100646.

6. Patel V, Kumar VK, Narayan A. Postural control and level of functional abilities with and without ankle foot orthosis in ambulatory children with cerebral palsy: a cross sectional study. J Yoga Phys Ther. 2019;9:300.

7. Prenton S, Kenney LP, Stapleton C, Cooper G, Reeves ML, Heller BW, et al. Feasibility study of a take-home array-based functional electrical stimulation system with automated setup for current functional electrical stimulation users with foot-drop. Arch Phys Med Rehabil. 2014;95(10):1870-7. https:// doi.org/10.1016/j.apmr.2014.04.027.

8. Schmit JM, Riley M, Cummins-Sebree S, Schmitt L, Shockley K. Functional task constraints foster enhanced postural control in children with cerebral palsy. Phys Ther. 2016;96(3):348-54. https://doi.org/10.2522/ptj.20140425.

9. Palisano R, Orlin M, Schreiber J. Campbell's physical therapy for children: management of neurologic conditions. 5th Edition. 2017. Elsevier Inc. St. Louis

10. Rathinam C, Mohan V, Peirson J, Skinner J, Nethaji KS, Kuhn I. Effectiveness of virtual reality in the treatment of hand function in children with cerebral palsy: a systematic review. J Hand Ther. 2019;32(4):426-34. https://doi.org/1 0.1016/j.jht.2018.01.006.

11. Graham HK, Rosenbaum P, Paneth N, Dan B, Lin JP, Damiano DL, et al. Cerebral palsy. Nat Rev Dis Primers. 2016;2(1):15082. https://doi.org/10.1038/ nrdp.2015.82.

12. Dursun N, Bonikowski M, Dabrowski E, Matthews D, Gormley M, Tilton A, et al. Efficacy of repeat Abobotulinumtoxin A (Dysport ${ }^{\oplus}$ ) injections in improving gait in children with spastic cerebral palsy. Dev Neurorehabil. 2020;23(6):368-74. https://doi.org/10.1080/17518423.2019.1687602.

13. Altschuck N, Bauer C, Nehring I, Böhm H, Jakobeit M, Schröder AS, et al. Efficacy of pre- fabricated carbon-composite ankle foot orthoses for children with unilateral spastic cerebral palsy exhibiting a drop foot pattern. J Pediatr Rehabil Med. 2019;12(2):171-80. https://doi.org/1 0.3233/PRM-170524.

14. Pool D, Valentine J, Bear N, Donnelly CJ, Elliott C, Stannage K. The orthotic and therapeutic effects following daily community applied functional electrical stimulation in children with unilateral spastic cerebral palsy: a randomized controlled trial. BMC Pediatr. 2015;15(1):154. https://doi.org/1 0.1186/s12887-015-0472-y.

15. Damiano DL, Prosser LA, Curatalo LA, Alter KE. Muscle plasticity and ankle control after repetitive use of a functional electrical stimulation device for foot drop in cerebral palsy. Neurorehabil Neural Repair. 2013;27(3):200-7. https://doi.org/10.1177/1545968312461716.

16. Karabay I, Öztürk GT, Malas FÜ, Kara M, Tiftik T, Ersöz M, et al. Short-term effects of neuromuscular electrical stimulation on muscle architecture of the tibialis anterior and gastrocnemius in children with cerebral palsy: preliminary results of a prospective controlled study. Am J Phys Med Rehabil. 2015;94(9):728-33. https://doi.org/10.1097/PHM.0000000000000238.

17. El-Shamy SM, Abdelaal AAM. WalkAide efficacy on gait and energy expenditure in children with hemiplegic cerebral palsy: a randomized controlled trial. Am J Phys Med Rehabil. 2016;95(9):629-38. https://doi.org/1 0.1097/PHM.0000000000000514.

18. Ghotbi N, Nakhostin Ansari N, Naghdi S, Hasson S. Measurement of lowerlimb muscle spasticity: intrarater reliability of Modified Ashworth Scale. J Rehabil Res Dev. 2011;48(1):83-8. https://doi.org/10.1682/JRRD.2010.02.0020.

19. Towns M, Rosenbaum P, Palisano R, Wright FV. Should the gross motor function classification system be used for children who do not have cerebral palsy? Dev Med Child Neurol. 2018;60(2):147-54. https://doi.org/1 $0.1111 /$ dmcn.13602.

20. Dawson N, Dzurino D, Karleskint M, Tucker J. Examining the reliability, correlation, and validity of commonly used assessment tools to measure balance. Health Sci Rep. 2018;1(12):1-8.

21. El-Shamy SM. Effects of antigravity treadmill training on gait, balance, and Fall risk in children with diplegic cerebral palsy. Am J Phys Med Rehabil. 2017;96(11):809-15. https://doi.org/10.1097/PHM.0000000000000752.

22. Bethoux F, Rogers H, Nolan K, Abrams G, Annaswamy T, Brandstater M, et al Long-term follow-up to a randomized controlled trial comparing peroneal nerve functional electrical stimulation to an ankle foot orthosis for patients with chronic stroke. Neurorehabil Neural Repair. 2015;29(10):911-22. https:// doi.org/10.1177/1545968315570325.

23. Pool D, Blackmore AM, Bear N, Valentine J. Effects of short-term daily community walk aide use on children with unilateral spastic cerebral palsy. Pediatr Phys Ther. 2014;26(3):308-17. https://doi.org/10.1097/PEP. 0000000000000057.

24. Morgan P, McDonald R, McGinley J. Perceived cause, environmental factors, and consequences of falls in adults with cerebral palsy: a preliminary mixed methods study. Rehabil Res Pract. 2015;2015:196395.

25. Bailes AF, Caldwell C, Clay M, Tremper M, Dunning K, Long J. An exploratory study of gait and functional outcomes after neuroprosthesis use in children with hemiplegic cerebral palsy. Disabil Rehabil. 2017;39(22):2277-85. https:// doi.org/10.1080/09638288.2016.1225827.

26. Jung T, Kim Y, Kelly LE, Abel MF. Biomechanical and perceived differences between overground and treadmill walking in children with cerebral palsy. Gait Posture. 2016;45:1-6. https://doi.org/10.1016/j.gaitpost.2015.12.004.

27. Wiart L, Rosychuk RJ, Wright FV. Evaluation of the effectiveness of robotic gait training and gait-focused physical therapy programs for children and youth with cerebral palsy: a mixed methods RCT. BMC Neurol. 2016;16(1):86. https://doi.org/10.1186/s12883-016-0582-7.

28. Wright PA, Durham S, Ewins DJ, Swain ID. Neuromuscular electrical stimulation for children with cerebral palsy: a review. Arch Dis Child. 2012; 97(4):364-71. https://doi.org/10.1136/archdischild-2011-300437. 
29. Mooney JA, Rose J. A scoping review of neuromuscular electrical stimulation to improve gait in cerebral palsy: the arc of progress and future strategies. Front. Neurol. 2019;10:887. https://doi.org/10.3389/fneur.2019. 00887.

30. Rose J, Cahill-Rowley K, Butler EE. Artificial walking technologies to improve gait in cerebral palsy: multichannel neuromuscular stimulation. Artif Organs. 2017;41(11):E233-9. https://doi.org/10.1111/aor.13058.

31. Fowler EG, Staudt LA, Greenberg MB. Lower-extremity selective voluntary motor control in patients with spastic cerebral palsy: increased distal motor impairment. Dev Med Child Neurol. 2010;52(3):264-9. https://doi.org/1 0.1111/j.1469-8749.2009.03586.x.

32. Mäenpää H, Jaakkola R, Sandström M, Von Wendt L. Effect of sensory-level electrical stimulation of the tibialis anterior muscle during physical therapy on active dorsiflexion of the ankle of children with cerebral palsy. Pediatr Phys Ther. 2004;16(1):39-44. https://doi.org/10.1097/01.PEP.0000114629.2 0513.7A.

33. Yiğitoğlu P, Kozanoğlu E. Effectiveness of electrical stimulation after administration of botulinum toxin in children with spastic diplegic cerebral palsy: A prospective, randomized clinical study. Turk J Phys Med Rehabil. 2019;65(1):16-23. https://doi.org/10.5606/tftrd.2019.2236.

34. Armstrong EL, Boyd RN, Kentish MJ, Carty CP, Horan SA. Effects of a training programme of functional electrical stimulation (FES) powered cycling, recreational cycling and goal-directed exercise training on children with cerebral palsy: a randomized controlled trial protocol. BMJ Open. 2019;9(6): e024881. https://doi.org/10.1136/bmjopen-2018-024881.

35. Seifart $A$, Unger $M$, Burger $M$. Functional electrical stimulation to lower limb muscles after botox in children with cerebral palsy. Pediatr Phys Ther. 2010; 22(2):199-206. https://doi.org/10.1097/PEP.0b013e3181dbd806.

36. Behboodi A, Zahradka N, Alesi J, Wright H, Lee SCK. Use of a novel functional electrical stimulation gait training system in 2 adolescents with cerebral palsy: a case series exploring neurotherapeutic changes. Phys Ther. 2019;99(6):739-47. https://doi.org/10.1093/ptj/pzz040.

37. Böhm H, Döderlein L, Dussa C. Functional electrical stimulation for foot drop in the upper motor neuron syndrome: does it affect 3D foot kinematics during the stance phase of walking? FussSprungg. 2020;18(2): 115-24. https://doi.org/10.1016/j.fuspru.2020.03.006.

\section{Publisher's Note}

Springer Nature remains neutral with regard to jurisdictional claims in published maps and institutional affiliations.

\section{Submit your manuscript to a SpringerOpen ${ }^{\circ}$ journal and benefit from:}

- Convenient online submission

- Rigorous peer review

- Open access: articles freely available online

- High visibility within the field

- Retaining the copyright to your article

Submit your next manuscript at $\boldsymbol{\nabla}$ springeropen.com 